\title{
Sensitivity of free tropospheric carbon monoxide to atmospheric weather states and their persistency: an observational assessment over the Nordic countries
}

\author{
M. A. Thomas ${ }^{1}$ and A. Devasthale ${ }^{2}$ \\ ${ }^{1}$ Air Quality Unit, Research and Development Department, Swedish Meteorological and Hydrological Institute (SMHI), \\ Norrköping, Sweden \\ ${ }^{2}$ Atmospheric Remote Sensing Unit, Research and Development Department, SMHI, Norrköping, Sweden
}

Correspondence to: M. A. Thomas (manu.thomas@smhi.se)

Received: 16 January 2014 - Published in Atmos. Chem. Phys. Discuss.: 4 April 2014

Revised: 25 September 2014 - Accepted: 29 September 2014 - Published: 3 November 2014

\begin{abstract}
Among various factors that influence the longrange transport of pollutants in the free troposphere (FT), the prevailing atmospheric weather states probably play the most important role in governing characteristics and efficacy of such transport. The weather states, such as a particular wind pattern, cyclonic or anticyclonic conditions, and their degree of persistency determine the spatio-temporal distribution and the final fate of the pollutants. This is especially true in the case of Nordic countries, where baroclinic disturbances and associated weather fronts primarily regulate local meteorology, in contrast to the lower latitudes where a convective paradigm plays a similarly important role. Furthermore, the long-range transport of pollutants in the FT has significant contribution to the total column burden over the Nordic countries. However, there is insufficient knowledge on the large-scale co-variability of pollutants in the FT and atmospheric weather states based solely on observational data over this region. The present study attempts to quantify and understand this statistical co-variability while providing relevant meteorological background.

To that end, we select eight weather states that predominantly occur over the Nordic countries and three periods of their persistency ( 3 days, 5 days, and 7 days), thus providing in total 24 cases to investigate sensitivity of free tropospheric carbon monoxide, an ideal tracer for studying pollutant transport, to these selected weather states. The eight states include four dominant wind directions (namely, NW, NE, SE and SW), cyclonic and anticyclonic conditions, and the enhanced positive and negative phases of the North Atlantic Oscillation (NAO). For our sensitivity analysis, we use recently released
\end{abstract}

Version 6 retrievals of $\mathrm{CO}$ at $500 \mathrm{hPa}$ from the Atmospheric Infrared Sounder (AIRS) onboard Aqua satellite covering the 11-year period from September 2002 through August 2013 and winds from the ECMWF's ERA-Interim project to classify weather states for the same 11-year period.

We show that, among the various weather states studied here, southeasterly winds lead to highest observed $\mathrm{CO}$ anomalies (up to $+8 \%$ ) over the Nordic countries while transporting pollution from the central and eastern parts of Europe. The second (up to $+4 \%$ ) and third highest (up to $+2.5 \%$ ) $\mathrm{CO}$ anomalies are observed when winds are northwesterly (facilitating inter-continental transport from polluted North American regions) and during the enhanced positive phase of the NAO respectively. Higher than normal CO anomalies are observed during anticyclonic conditions (up to $+1 \%$ ) compared to cyclonic conditions. The cleanest conditions are observed when winds are northeasterly and during the enhanced negative phases of the NAO, when relatively clean Arctic air masses are transported over the Nordic regions in the both cases. In the case of nearly all weather states, the $\mathrm{CO}$ anomalies consistently continue to increase or decrease as the degree of persistency of a weather state is increased. The results of this sensitivity study further provide an observational basis for the process-oriented evaluation of chemistry transport models, especially with regard to the representation of large-scale coupling of chemistry and local weather states and its role in the long-range transport of pollutants in such models. 


\section{Introduction}

Apart from the local sources of pollution that degrade local air quality and hence human health, many studies show that, depending on the global and regional circulation patterns and favourable meteorological conditions, the long-range transport of pollutants also contributes to increased pollutant concentrations. In fact, the importance of hemispheric and longrange transport of pollutants is now widely recognized in the scientific community, and the research focus in recent years has deservedly been on better characterization of source-tosink relationships and drivers of pollutant variability during such transport (Li et al., 2002, 2005; Stohl et al., 2002; Creilson et al., 2003; Eckhardt et al., 2003; Trickl et al., 2003; Duncan and Bay, 2004; Pfister et al., 2004; Huntrieser et al., 2005; Chin et al., 2007; Shindell et al., 2008; Fiore et al., 2009; Dentener et al., 2010; Brandt et al., 2012; Christoudias et al., 2012; Lin et al., 2012). It is important to keep in mind that it is the local meteorology and synoptic-scale weather patterns that eventually determine the spatio-temporal distribution of pollutants, their transport characteristics and final fate. One of the main mechanisms by which the pollutants (e.g. from wildfire emissions) get transported from their source regions to the Earth's northernmost latitudes as far as the Arctic is through varying states of atmospheric circulation. This was first realized through the phenomenon of Arctic haze observed during the winter/spring months that was first reported in the 1950s (Quinn et al., 2007). It is now known that the major pathways to the Arctic depend upon the season and the position of the Arctic front. For example, during the winter and spring months, the intense Siberian highpressure system pushes the Arctic front towards the south whereby the polluted regions of the Eurasian subcontinent are within the Arctic air mass resulting in the efficient transport of pollutants during this time of the year.

The spatio-temporal distribution of pollutants over the Nordic countries is a result of complex interplay of local sources, atmospheric circulation patterns, and contributions from the long-range transport originating from North America, continental Europe and Asia. The dominant modes of atmospheric variability in the Northern Hemisphere affecting the Nordic countries, especially in winter, are the North Atlantic Oscillation (NAO) and Arctic Oscillation (AO). The positive and negative phases of NAO are marked by changes in the wind speed and direction over the Atlantic, heat and moisture transport across the Atlantic. The frequency and intensity of the number of storms and warm conveyer belts influence the transatlantic transport of pollutants from North America to Europe, including over the northern European latitudes (Li et al., 2002; Hurrel et al., 2003; Duncan and Bey, 2004; Dentener et al., 2010). Eckhardt et al. (2003) observed a strong correlation between the NAO and transport of anthropogenic pollution into the Arctic and eastern Europe from all the Northern Hemisphere continents with an enhanced transport during the positive NAO phase. However, a significant anti-correlation is observed between NAO and the anthropogenic pollutants over western and central Europe (Christoudias et al., 2012). Significant correlations between the positive phase of AO and elevated ozone concentrations in western Europe is observed and can be attributed largely to in situ production associated with the subsidence within the high-pressure dome or entrainment of pollutants into this dome (Creilson et al., 2003). Pfister et al. (2004) showed that when averaged over Europe, almost $67 \%$ of the anthropogenic carbon monoxide (CO) at the surface comes from regional sources, in addition to the transport from North America (14\%) and Asia (15\%). However, at higher altitudes, the contribution from North America and Asia is significantly higher. Brandt et al. (2012) using the 3-D longrange chemistry transport hemispheric model showed that the contributions from North American anthropogenic emissions to the ozone levels in European subcontinent is 3.1\% and the contributions from European anthropogenic sources to North America is $0.9 \%$.

One of the major pathways carrying pollutants from the continental Europe to the Arctic passes over the Nordic countries. Tang et al. (2009) studied the long-range transport and weather patterns relating to high ozone events in southern Sweden, and using a trajectory model showed that these events occurred during anticyclonic events, especially during summer. But they observed strong negative relationship between cyclonic and high ozone events. Recently, Devasthale and Thomas (2012) investigated co-variation of temperature inversions and $\mathrm{CO}$ over Scandinavia during winter using satellite sensor data. They showed that the increased levels of $\mathrm{CO}$ are observed when the atmosphere is thermodynamically unstable (weaker or negative inversion strength) and when the westerly winds are strong. Apart from long-range transport of pollutants in the free troposphere (FT), in cold climate of the Nordic countries, unfavourable meteorological conditions such as thermal inversions, low boundary layer height and low temperatures can contribute to increased pollutant concentrations in the lowermost troposphere near the surface. The above-mentioned studies emphasize the need for a better quantification of the linkages between the pollutant concentrations and atmospheric weather states.

Many of the studies mentioned above examine $\mathrm{CO}$, since $\mathrm{CO}$ is often considered as an excellent tracer to investigate pollution transport characteristics due to its moderate lifetime in the atmosphere. Increased carbon monoxide levels would not only enhance carbon dioxide levels in the atmosphere through its reaction with hydroxyl $(\mathrm{OH})$ radicals, but also indirectly increase concentrations of short-lived climate pollutants such as ozone and methane, which would otherwise be depleted by $\mathrm{OH}$ radicals. Therefore, monitoring $\mathrm{CO}$ and understanding its sensitivity to large-scale weather patterns, based solely on observations, is important not only to gain insights into long-range pollution transport, but also to serve as an observational basis for the sensitivity studies to evaluate chemistry transport models. 
In spite of their importance as mentioned above, there is no consistent observationally based assessment of how the dominant weather states impact FT CO variability over the Nordic countries. The present study attempts to partially fill this gap. Decreased instrument sensitivity over very cold surfaces, variable snow cover and difficulties in cloud detection are some of the factors that limit the use of satellite remote sensing to study the atmospheric composition variability over the Nordic regions, especially in the lowermost troposphere. But the data records of atmospheric composition from satellite sensors, especially from hyperspectral sounders such as IASI (Clerbaux et al., 2009) and AIRS (Chahine et al., 2006), are continuously improving and we now have better understanding of their retrieval quality and sensitivities. More than a decade long data, e.g. from AIRS and MOPITT, can be exploited to investigate statistics on the large-scale co-variability of weather states and trace gases, as attempted here.

In the next section, we describe the data set used and methodology adopted, followed by presentation of an overview of dominant atmospheric circulation patterns and corresponding meteorological conditions over the Nordic region, with specific focus on Sweden, in Sect. 3. We then discuss sensitivity of $\mathrm{CO}$ to these patterns and persistency of these patterns in Sect. 4. The final section presents conclusions.

\section{The Atmospheric Infrared Sounder (AIRS) CO and ERA-Interim data sets}

AIRS onboard Aqua satellite has 2378 hyperspectral channels, out of which about 36 well-defined channels with wavenumbers ranging from 2181.49 to $2221.12 \mathrm{~cm}^{-1}$ are used in $\mathrm{V} 6$ to retrieve $\mathrm{CO}$ (http://disc.sci.gsfc.nasa.gov/AIRS/documentation/v6_ docs/v6releasedocs-1/V6_Retrieval_Channel_Sets.pdf). A priori profiles (sets of 100 layers) with monthly granularity are used as a first guess. The profiles are based on MOZART (Model for OZone And Related chemical Tracers) monthly mean hemispheric profiles (http://disc.sci.gsfc.nasa.gov/AIRS/documentation/v6_docs/ v6releasedocs-1/V6_CO_Initial_Guess_Profiles.pdf). By varying the geophysical state, the retrieval algorithm for $\mathrm{CO}$ basically tries to minimize the weighted difference between clear-sky radiance and the radiance computed using a forward model. Using averaging kernels, the retrieval algorithm relates estimated CO profile to "true" profile and a priori information. The algorithm details are described in Susskind et al. (2003) and in Warner et al. (2007, 2010, and 2013).

We use the recently released Version 6, daily standard and support Level 3 retrievals of CO (AIRS Science Team/Joao Texeira, 2013; AIRS-V6L3UG, 2013). Eleven years of data from September 2002 to (and including) August 2013 are analysed. The AIRS retrievals of temperature and $\mathrm{CO}$ are validated and matured considerably over the years to enable variability studies (Divakarla et al., 2006; Fetzer, 2006; Warner et al., 2007, 2010, 2013; Yurganov et al., 2008). The accuracy and biases of AIRS CO are well documented in the studies mentioned above.

Since the focus of the present study is on the FT, we have analysed $\mathrm{CO}$ at four different vertical levels, namely $850 \mathrm{hPa}, 700 \mathrm{hPa}, 500 \mathrm{hPa}$ and $400 \mathrm{hPa}$, but the results are shown only for $500 \mathrm{hPa}$. The reasons for that are (a) the signal of pollutant transport in the FT is most tangible at this level, (b) coincidentally, AIRS retrievals are of best quality at this level (Yurganov et al., 2008; Warner et al., 2010), and (c) for the sake of brevity. The tendencies in $\mathrm{CO}$ observed at these four vertical levels and corresponding wind patterns during selected weather states are not significantly different, since many of the weather states, when they are persistent, affect the entire FT (as shown later).

We analyse AIRS retrievals only when the degrees of freedom value is larger than 0.5 . For investigating large-scale features and tendencies, as attempted in the present study, AIRS Level 3 CO data are quite suitable, as for example shown by Devasthale and Thomas (2012). Data from both ascending and descending passes of the afternoon Aqua satellite are used. We have allowed up to $30 \%$ cloud cover while analysing the AIRS CO retrievals based on the findings of our sensitivity studies (Devasthale and Thomas, 2012) and previous experience with AIRS data (Devasthale et al., 2010, 2011, 2012, 2013). Susskind et al. (2003) have previously presented detailed analysis of the accuracy of AIRS retrievals in the presence of clouds. The yield and accuracy of AIRS retrievals should not degrade significantly up to $30 \%$ cloud cover. Recently, Warner et al. (2013) showed that the AIRS $\mathrm{CO}$ retrievals in cloud-contaminated cases are of comparable quality. The degrees of freedom of the signal, an indicator of information content, are reduced only by up to 0.2 in cloudy cases (please refer Figs. 3 and 4 in Warner et al., 2013). The difference should even be smaller in our cases, since we allow only $30 \%$ cloud contamination. Furthermore, the majority of opaque clouds occurring over the study area are low clouds (cloud tops less than $700 \mathrm{hPa}$ ). Since we analysed retrievals at $500 \mathrm{hPa}$, the cloud impact is estimated to be small. Finally, the absence of any spatial correlation between cloud fraction and observed $\mathrm{CO}$ anomalies also suggests that the cloud impact is negligible.

The advantage of using AIRS data lies in the fact that (a) the simultaneous retrievals of temperature and humidity in time and space are available which can be used to understand thermodynamical properties of the atmosphere and possible transport of heat and moisture during different weather states, (b) the longest (> 11 year) data record of $\mathrm{CO}$ from hyperspectral measurements is available, and (c) the synergy with other A-Train sensors providing aerosol and cloud information can be exploited in future studies. 
For investigating winds, we used 6-hourly zonal $(u)$ and meridional $(v)$ wind components from the ECMWF's ERAInterim reanalysis (Dee et al., 2011) for the same period when AIRS CO data are available.

\section{An overview of selected weather states}

In the present study, we select eight weather states that most frequently occur over the study area $\left(42-80^{\circ} \mathrm{N}, 10^{\circ} \mathrm{W}-\right.$ $\left.40^{\circ} \mathrm{E}\right)$. Figures $1-5$ show an overview of circulation patterns and typical meteorological conditions observed under these weather states. The states are selected based on the synthesis of previous literature (e.g. Chen, 2000; Linderson, 2001) and further confirmed by manual inspection of numerous weather reports from the Swedish Meteorological and Hydrological Institute. Since the persistency of a weather state may enhance or reduce pollution levels in the FT, for each selected weather state, we have also investigated tendencies of $\mathrm{CO}$ anomalies under three persistency periods, namely 3 days (P3), 5 days (P5) and 7 days (P7). For brevity, we present the circulation patterns and meteorological conditions only for the P5 case, but the sensitivity results for $\mathrm{CO}$ are shown for all weather states and persistency periods later in this study.

The eight identified weather states consist of four dominant wind directions (NW, NE, SE and SW), anticyclonic and cyclonic conditions, and two enhanced phases of the NAO. In the case of the first four weather states, we chose the centre $\left(55-60^{\circ} \mathrm{N}, 12-20^{\circ} \mathrm{E}\right)$ of the study area $\left(45-80^{\circ} \mathrm{N}, 10^{\circ} \mathrm{W}-\right.$ $40^{\circ} \mathrm{E}$ ) to average daily wind speed and direction at $850 \mathrm{hPa}$ from the ERA-Interim reanalysis. Based on these daily averages we selected days when a particular wind direction prevailed and persisted for at least 3,5 and 7 days. The same procedure is applied for selecting anticyclonic and cyclonic conditions based on average mean sea level pressure (MSLP) over the centre of the study region. For the remaining two weather states, the selection of days is based on NAO indices. The overlapping dates among weather states are intuitively avoided by the algorithm. For example, if a certain day is assigned to a certain weather state, then that day is not considered further in the statistics of other weather states. But the selected days are inclusive within the persistency periods of the same weather state. For example, when a weather state persists for 7 consecutive days, then the first three and five days of such event are included in the corresponding P3 and P5 cases. We analysed weather state data in the following order. First, the time information for P3, P5, and P7 for the NAO cases are obtained, followed by the analysis for anticyclonic and cyclonic conditions and finally for the wind directions (clockwise NW, NE, SE, SW).

During the selected 11-year study period, relatively speaking, these states (i.e. NW, NE, SE, SW, anticyclonic and cyclonic, and EP and EN) occur 9, 3, 4, 14, 28, 27, 6 and $9 \%$ of the time respectively. The number of events studied for each state is mentioned in Table 1 . The probability of a par-
Table 1. The number of events studied for each of the weather state and its persistency.

\begin{tabular}{lrrr}
\hline & P3 & P5 & P7 \\
\hline NW & 180 & 72 & 26 \\
NE & 85 & 31 & 11 \\
SE & 63 & 25 & 9 \\
SW & 280 & 100 & 38 \\
Anticyclonic & 556 & 224 & 74 \\
Cyclonic & 540 & 218 & 78 \\
EP & 121 & 48 & 17 \\
EN & 178 & 72 & 25 \\
\hline
\end{tabular}

ticular weather state prevailing over the study area decreases with increasing persistency. Consequently, the results for 7day periods, shown later, are in some cases patchy. However, the $\mathrm{CO}$ anomalies exceed at least one standard deviation and hence are significant.

Figures 1 and 2 show the composites of wind direction and strength at $850 \mathrm{hPa}$ for the $\mathrm{P} 5$ case for much broader area to better understand the pathways of the air masses entering the study area. The actual study area is marked by the black rectangle.

When the winds are of NW origin, the air masses are transported from across the northernmost Atlantic into the Nordic countries and eastern Europe (Fig. 1a). This results in colder than average temperatures and drier conditions in the eastern parts of the study area and warmer and moist conditions in the west as reflected in Fig. 5 which shows the corresponding temperature anomalies. However, when the winds have a NE component, the air masses transported across the Atlantic from North America travel northward almost perpendicular to the latitude belts up to $75^{\circ} \mathrm{N}$ are merged with the Arctic air mass and merges with the anticyclonic flow with the centre of this flow located over southern Norway (Fig. 1b). This anticyclonic flow further transports heat from the continental Europe and eastern Atlantic over the Norwegian Sea as visible in Fig. 5. In the SW case, it can be seen that the air masses that travel to Scandinavia likely originate from a much higher trajectory (north of $50^{\circ} \mathrm{N}$ ) in North America and are mixed with East Atlantic gyre (Fig. 2a). The warm winds from the southerly latitudes (in comparison to the NW case) cause warming of the middle troposphere over much of the eastern study area (Fig. 5). The anticyclonic flow centred over Finland in the SE case draws in warm air masses from the central and eastern parts of Europe (Fig. 2b) also resulting in warmer temperatures (Fig. 5).

Another important characteristic of the Earth's atmosphere is pressure distribution as it defines the wind and weather patterns globally. Figure 3 shows the composites of the magnitude and wind direction at $850 \mathrm{hPa}$ during high MSLP conditions and low MSLP conditions over the centre of the study. During high MSLP conditions, the winds seem to favour the transatlantic transport towards the northernmost latitudes. 


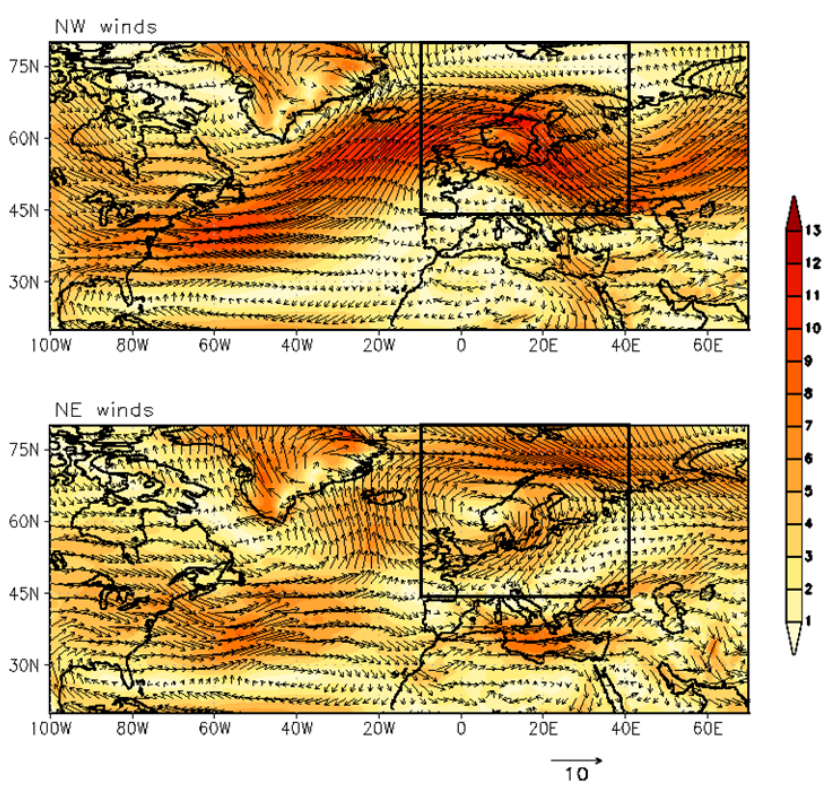

Figure 1. Atmospheric circulation patterns at $850 \mathrm{hPa}$ when winds (in $\mathrm{m} \mathrm{s}^{-1}$ ) are NW and NE over the centre of the study area. The colourbar indicates wind strength (in $\mathrm{ms}^{-1}$ ). The study area is marked with black rectangle.

The anticyclonic flow further circulates air masses from continental Europe to over the Norwegian Sea and the northern parts of the study area. On the other hand, during low MSLP conditions, the winds have a much lower trajectory in the Atlantic and the air masses advected from across the Atlantic are transported over continental Europe and are caught up in the cyclonic flow centred around central Scandinavia. The circulation pattern during anticylonic (cyclonic) conditions leads to enhanced (reduced) heat and moisture transport over the western part of Scandinavia and Northeast Atlantic Ocean as shown in Fig. 5.

The gradients in pressure and hence, the winds, force different types of oscillations. One such prominent oscillation, manifested in boreal winter as a see-saw in pressure over the Atlantic, is the North Atlantic Oscillation. As described in the Introduction, the NAO phases play an important role in the transatlantic transport of pollutants. Shown in Fig. 4 are respectively the $850 \mathrm{hPa}$ winds associated with enhanced positive (EP: NAO index $>+1$ ) and enhanced negative NAO conditions (EN: NAO index <-1) and when these conditions prevail for at least five consecutive days. The daily NAO index for the period in study was downloaded from the following link http://www.cpc.ncep.noaa.gov/products/precip/ CWlink/pna/nao.shtml. The NAO index itself does not show any significant trend during the last decade as shown in the Supplement Fig. S1.

During the enhanced positive NAO phase, the winds are stronger and there is a significant advection of air masses across the Atlantic from northern US and Canada into north-

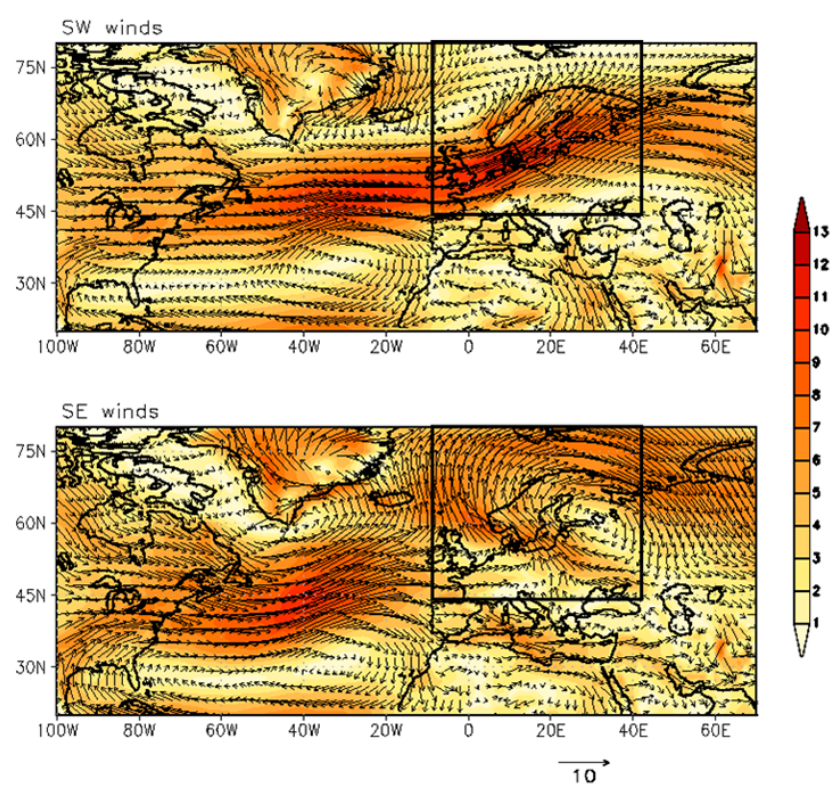

Figure 2. Same as in Fig. 1, but for the SW and SE directions.

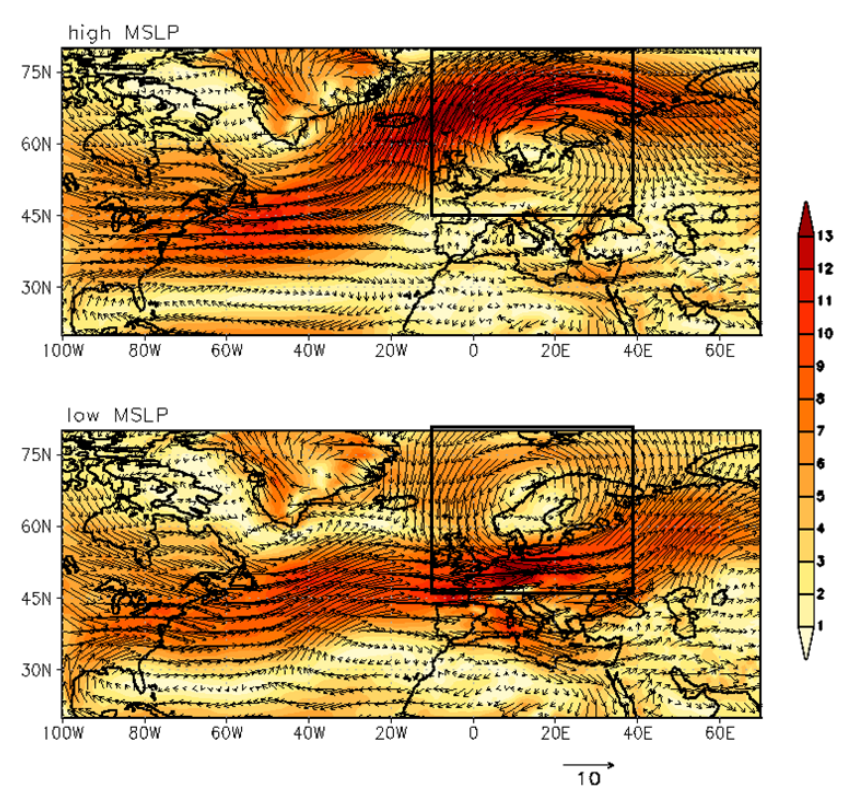

Figure 3. Atmospheric circulation patterns at $850 \mathrm{hPa}$ during high and low MSLP conditions.

ern Europe and Scandinavia (Fig. 4a). In fact, there is striking resemblance between warmer temperature anomalies (Fig. 5) and wind pattern in the EP case, suggesting the efficiency of atmospheric transport. During the EN phase, the winds are much weaker (Fig. 4b) and the cold Arctic air masses propagate into Scandinavian countries (also clearly visible in Fig. 5) and there is a relatively stronger southwesterly flow over northern Europe.

The normalized frequency of number of days of data available for each weather state as function of months is shown 


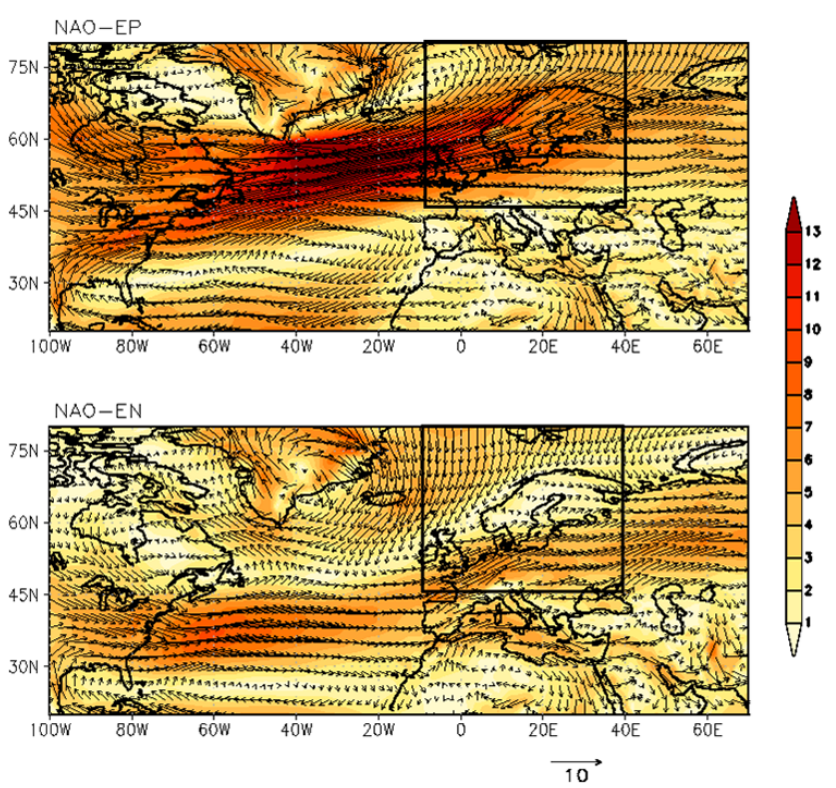

Figure 4. Atmospheric circulation patterns at $850 \mathrm{hPa}$ during enhanced positive and negative phases of NAO.

in Fig. 6. The distribution of their occurrence is not always uniform as expected, since different weather states are dominant during different times of a year except for anticyclonic and cyclonic periods (i.e. during above normal and below normal MSLP conditions) when their occurrences are distributed evenly. The frequency distribution of EP and EN phases is such that the enhanced positive NAO phases are more prominent during the winter half of the year, while the enhanced negative NAO phases are more prominent during the other half of the year. This unequal distribution of samples as a function of months makes it difficult to compare their relative impact of weather states on observed $\mathrm{CO}$ levels due to interference of seasonality of $\mathrm{CO}$. To address this, we calculate 11-year annual climatology of $\mathrm{CO}$ by taking a weighted average based on the distribution of occurrence for a particular state as a function of month as follows:

$C=\sum_{i=1}^{12} w_{i} c_{i}$

where $i$ is month, $w_{i}$ is monthly weight (based on figure shown above), $c_{i}$ is monthly climatology of CO.

We then subtract this climatology from the composite of $\mathrm{CO}$ observed during that state to compute anomalies. This ensures that we remove the seasonal variations while comparing different states and that the observed $\mathrm{CO}$ anomalies are indeed due to contribution from that particular weather state and its persistency.
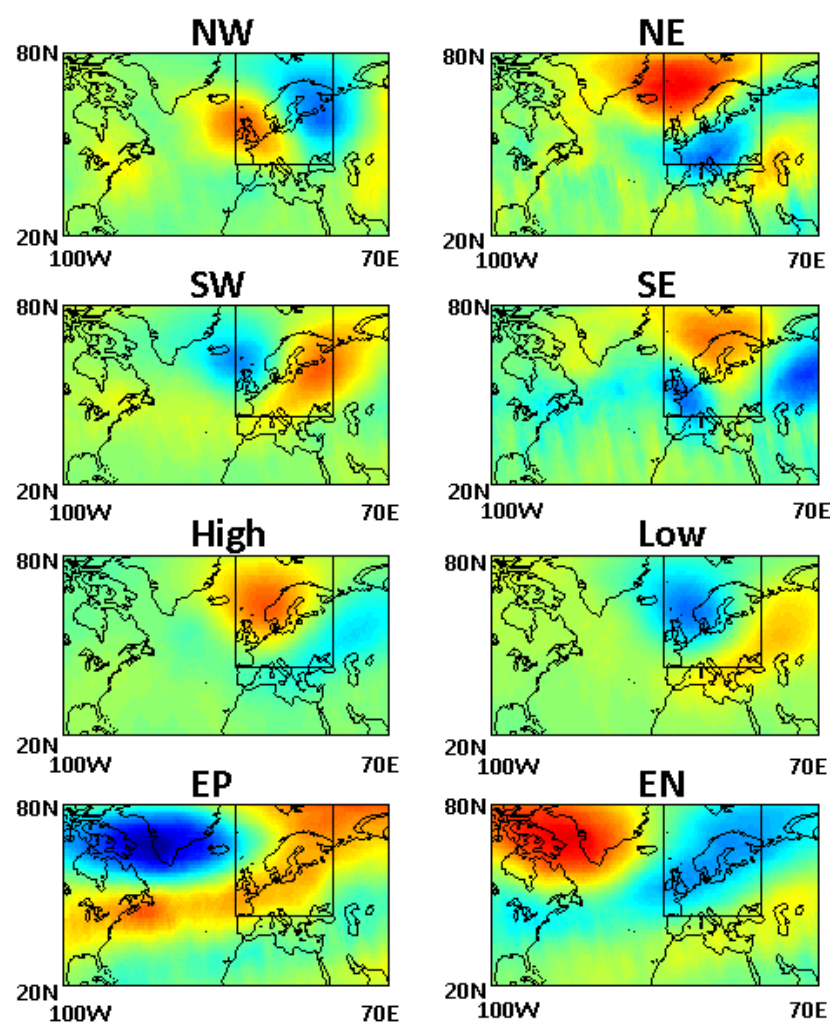

$-5$

5

Figure 5. Temperature anomalies at $850 \mathrm{hPa}$ [in $\mathrm{K}]$ observed during selected weather states.

\section{Sensitivity of CO to weather states and their persistency}

The sources of $\mathrm{CO}$ over the study are mainly anthropogenic resulting from fossil fuel burning, vehicular emissions and industrial activities. The biomass burning (natural and anthropogenic) also contributes to the total CO budget. The seasonality in photochemical production and depletion gains importance with increasing altitude. This in combination with long-range and inter-continental transport drives the seasonal variability of $\mathrm{CO}$ in the free troposphere over the study area. The climatological seasonal distribution of $\mathrm{CO}$ at $500 \mathrm{hPa}$ over the study area is shown in Fig. S2. As expected the CO concentrations are higher in the late winter to early spring due to their increased lifetime as the photochemical loss is at its minimum because of the lack of sunlight, and due to increased emissions and efficient transport during this time of the year.

Figure 7 shows $\mathrm{CO}$ anomalies in the free troposphere $(500 \mathrm{hPa})$ for four chosen wind directions and persistency periods of $\mathrm{P} 3, \mathrm{P} 5$ and $\mathrm{P} 7$. Only statistically significant anomalies exceeding one standard deviation are shown. When the winds are NW, above normal $\mathrm{CO}$ concentrations are observed over northern Europe and $\mathrm{CO}$ anomalies increase 


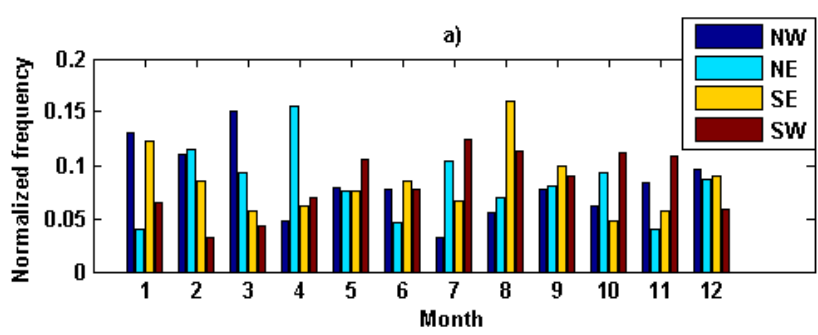

b)
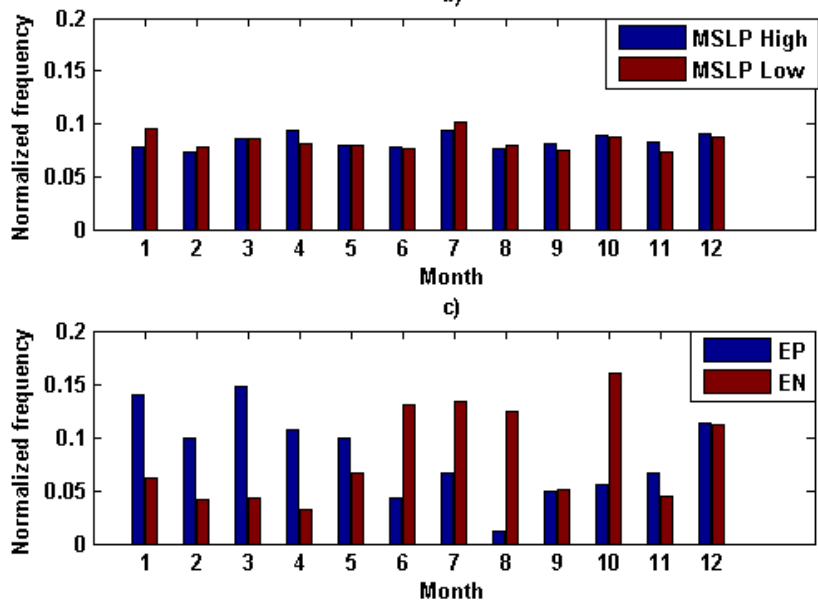

Figure 6. Normalized distribution of the number of weather events as a function of month when they persisted for 5 days for (a) wind directions, (b) anticyclonic and cyclonic cases and (c) for enhanced positive and negative NAO.

significantly from P3 to P7. The examination of circulation patterns and meteorological conditions for this weather state suggests that the NW air masses may efficiently transport pollutants from across the Atlantic into the study region. The wind speed also increases from P3 to P7. However, a different picture is observed when the winds are from $\mathrm{NE}$ directions. In the P3 case, $\mathrm{CO}$ concentrations are much higher towards central Europe compared to the Nordic countries. As the persistency of NE winds increases (from P3 to P7), reduced CO levels are observed and the FT becomes comparatively clean. This can be explained by the fact that the transatlantic pollutants that assimilate into the cyclonic flow observed during the NE cases are diluted by the even stronger and cleaner Arctic air mass intrusions into Scandinavia in the P7 period. When the winds are SE, as mentioned before, the major pathway of pollution transport into the Nordic countries is from central and eastern Europe, as seen in Fig. 2. Comparatively much lower $\mathrm{CO}$ anomalies are observed when the winds are SW. This may be because the air masses that travel to northern Europe have their source regions from northern North American subcontinent (north of $45^{\circ} \mathrm{N}$ ) which is comparatively cleaner than the air masses from other wind directions. The southwesterly winds are further mixed with cleaner air masses by the Atlantic gyre.
The deviation of the $\mathrm{CO}$ concentrations under anticyclonic and cyclonic conditions and their persistency is shown in Fig. 8. The $\mathrm{CO}$ concentrations are in general higher over northern Europe during anticyclonic conditions compared to cyclonic. The $\mathrm{CO}$ concentrations continue to increase as anticyclonic conditions persist, and vice versa for cyclonic situations. A careful analysis of wind patterns reveal that, during anticyclonic conditions, the polluted air masses from continental Europe and North America are being drawn and circulated over the Nordic regions whereas, during cyclonic conditions, cleaner Arctic air is mixed in the circulation gyre thereby being more efficient in the removal and dispersal of pollutants resulting in relatively cleaner conditions.

Lastly, the sensitivity of $\mathrm{CO}$ to NAO phases and their persistency is shown in Fig. 9. The $\mathrm{CO}$ anomalies are higher during the EP phase compared to the EN phase during all persistency periods. Furthermore, there is a clear tendency that, as the positive phases of the NAO persist, $\mathrm{CO}$ concentrations tend to increase, especially in the higher latitudes. The free troposphere on the other hand becomes cleaner when the negative phases of NAO persist. When the westerlies are weakened, cold and clean Arctic air is drawn over northern Europe during the negative phase. The tendencies in $\mathrm{CO}$ observed during positive and negative phases of NAO are consistent with previous studies that use models simulations (Eckhardt et al., 2003; Christoudias et al., 2012). For example, from the analysis of 15-year simulations, Eckhardt et al. (2003) show enhanced tracer transport to the Arctic that passes over the Nordic countries during positive phases of the NAO. Christoudias et al. (2012) arrive at a similar conclusion with regard to transport towards northern Europe.

To quantify the importance of the different synoptic states, Fig. 10 shows the percentage change in $\mathrm{CO}$ in the FT observed during the different weather states and persistency periods over the study area. It can be seen that in nearly all the cases, the $\mathrm{CO}$ concentrations either steadily increased or decreased with increased persistency of each weather state. The highest $\mathrm{CO}$ contribution, almost 4-8\% depending on the degree of persistency, is observed when the winds had a southeasterly component. The second (up to $4 \%$ ) and third highest $(2.5 \%)$ anomalies are observed during NW winds and the enhanced positive phases of the NAO respectively. The CO anomalies of completely opposite signs during positive and negative phases of the NAO confirm the significance of the role of natural variability in pollutant transport and diffusion. The anticyclonic and cyclonic conditions also show opposite signs of $\mathrm{CO}$ anomalies, with maximum anomalies in the order of $1 \%$ observed during anticyclonic conditions. The remaining weather states discussed in this study are more efficient in reducing the build-up of $\mathrm{CO}$ concentrations in the FT, thereby leading to cleaner conditions.

It is to be kept in mind that these percentage changes in FT CO are based on averages and that the individual shortterm intrusion of pollution or strong but short-lived episodic 

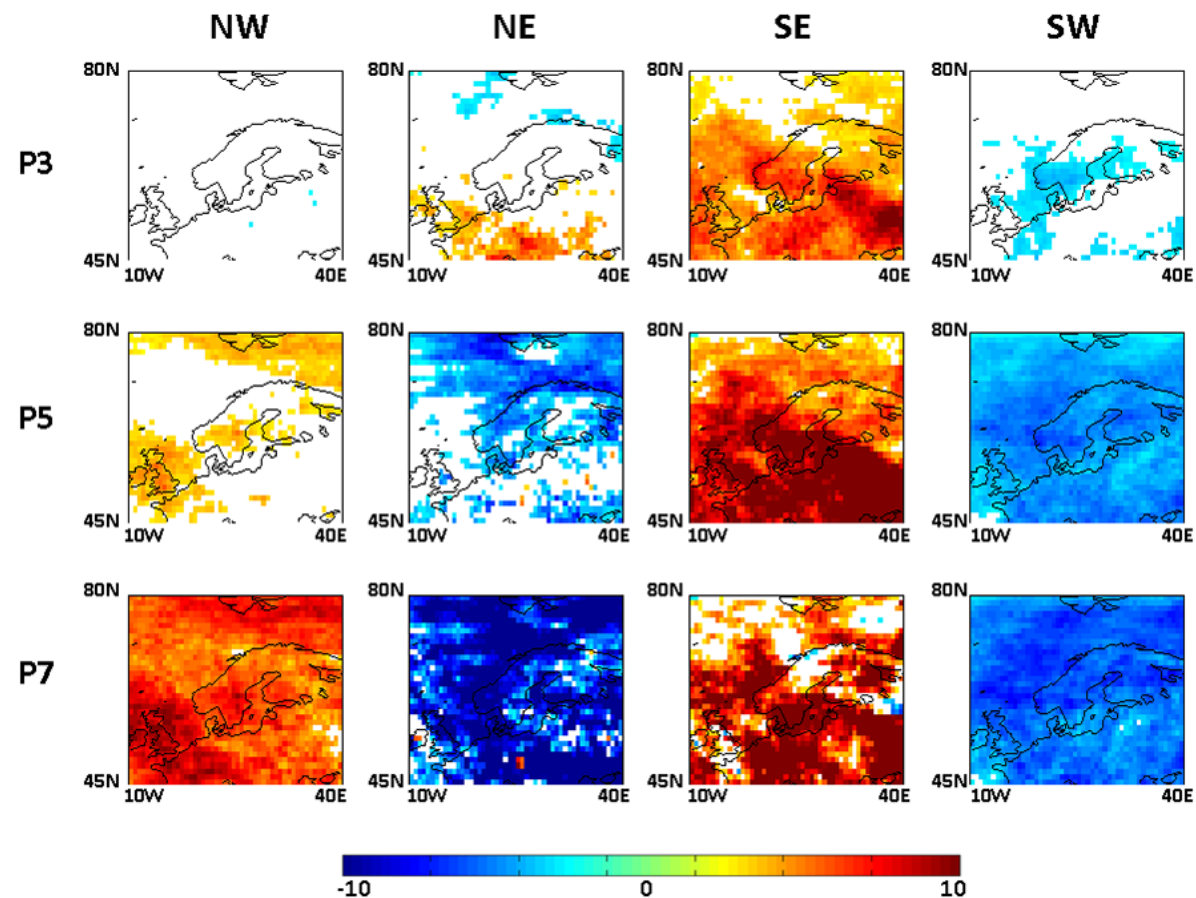

Figure 7. CO anomalies (in ppbv) at $500 \mathrm{hPa}$ observed under different wind conditions and their persistency periods. Only those anomalies exceeding one standard deviation are shown.
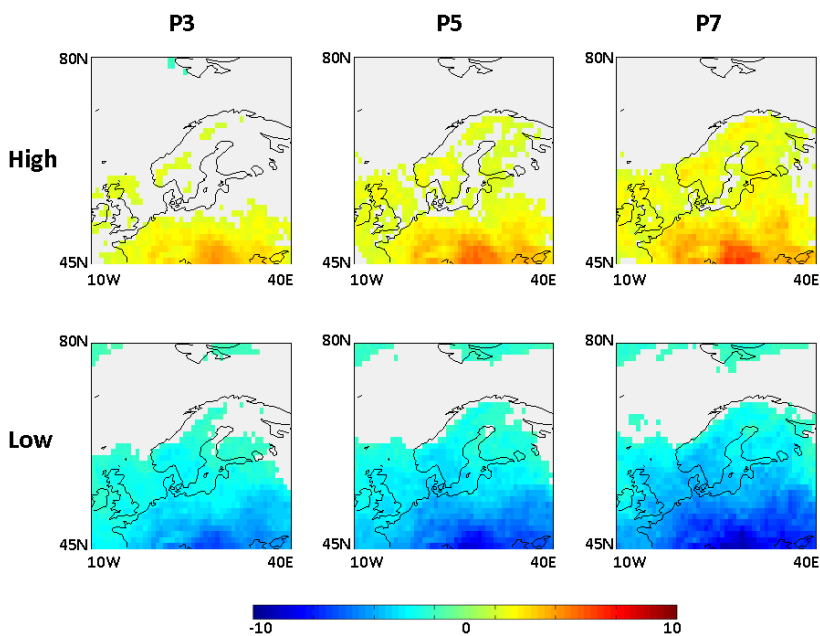

Figure 8. As Fig. 7, but under high and low MSLP conditions and their persistency periods.

transport can lead to much higher changes in $\mathrm{CO}$ over the study area.

As mentioned in Sect. 2, although we show results of $\mathrm{CO}$ variability at $500 \mathrm{hPa}$, we have investigated this variability at four different levels in the FT and in the total column $\mathrm{CO}$ as well. As the persistency period of the chosen weather states increases, it is expected to affect the $\mathrm{CO}$ variability in the entire troposphere in a systematic manner. This is evident in Fig. S3 which shows an example of the impact of wind di-
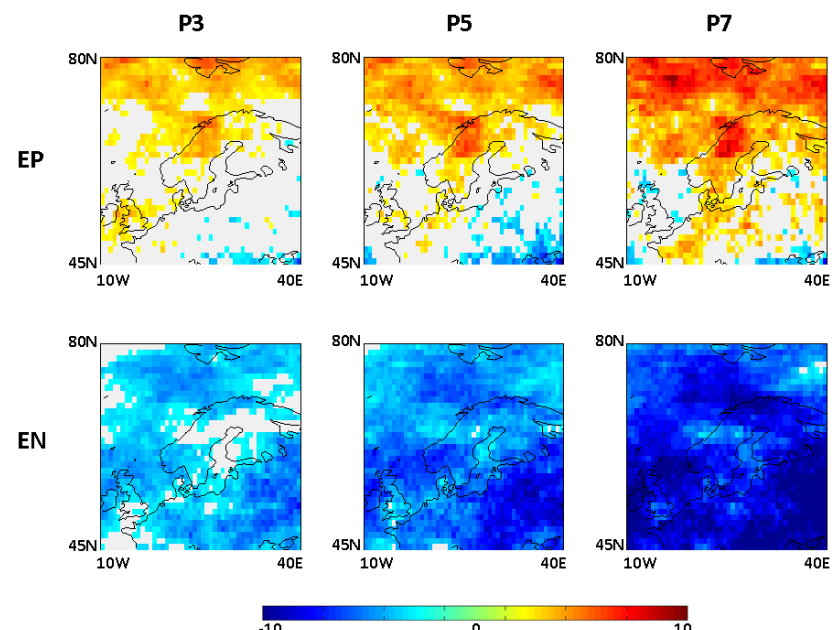

Figure 9. As Fig. 7, but under enhanced positive and negative phases of NAO and their persistency periods.

rections on the total column $\mathrm{CO}$ variability. The tendencies in $\mathrm{CO}$ total column anomalies under different wind directions and across persistency periods are strikingly similar to those observed at $500 \mathrm{hPa}$. This underscores the importance of the chosen weather states in regulating $\mathrm{CO}$ variability in the entire troposphere. Under certain conditions, for example very cold winters and surfaces, the sensitivity and information content of AIRS may peak only in the middle troposphere and the total column values are affected by this problem. But 


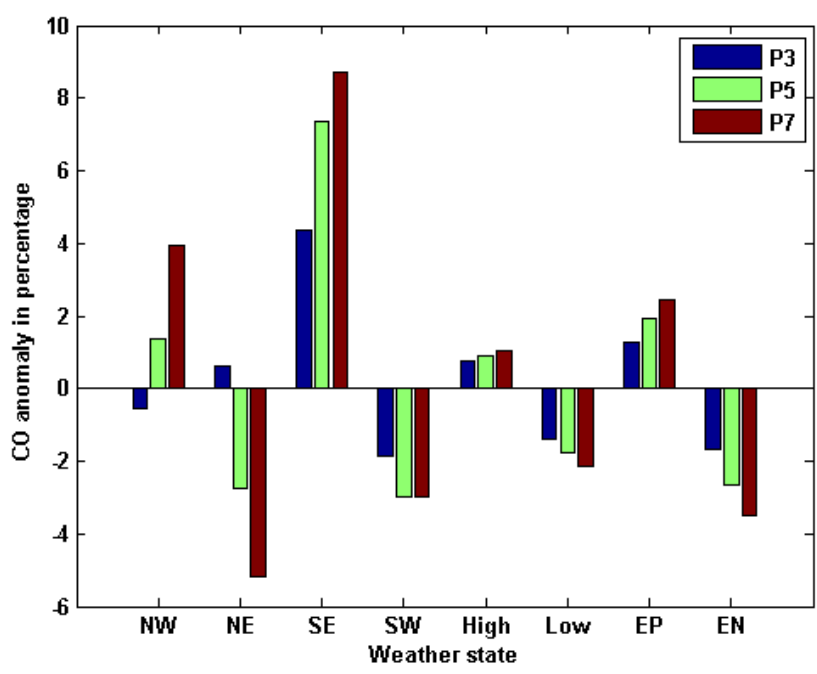

Figure 10. Percentage increase or decrease in $\mathrm{CO}$ at $500 \mathrm{hPa}$ observed during different weather states and their persistency periods compared to respective weighted climatologies over the study area.

keeping in mind that our samples are spread across the entire year (not just in winter months) and that the tendencies in $\mathrm{CO}$ anomalies are corroborated by wind and temperature anomaly patterns, it is most likely that the results shown in Fig. S3 are realistic.

Finally, it must be mentioned that there are two mechanisms that are not considered in the present study while interpreting the results. They are deep convection and warm conveyor belts (Madonna et al., 2014), both of which will lead to rapid transport of pollutants and thus are likely to contribute to the observed anomalies. We argue that the impact of the convective mixing is minimal due to the following reasons. Firstly, the boundary layer is decoupled from the FT most of the year due to the presence of inversions over the study region (Devasthale and Thomas, 2012). Then the likelihood of strong episodic vertical injections of pollutants exists only during summer months (via dry or moist convection), but it is very small since such events are usually few in number. And finally, in the FT $(850-400 \mathrm{hPa})$, the atmospheric variability over the study region is governed by the large-scale frontal systems created by the baroclinic disturbances (esp. in the winter half of the year). These systems provide a conducive environment for the advective rather than the local convective transport. Our study area is usually at the receiving end of such systems that often arrive from the neighbouring oceanic areas (Northeast Atlantic, North Sea, or the Arctic Ocean) or from the continental Europe.

The other transport mechanism, i.e. warm conveyor belts, will intrinsically be included in some of the weather states studied here, especially in those cases where winds have history over the North Atlantic. But it should be noted that, irrespective of the mechanism that triggered the transport of pollutants from the source regions, it is the local weather state over our study area that will regulate the distribution of these pollutants. For example, a particular weather state may either dampen the isentropic transport of pollutants or facilitate it further to other regions (e.g. to the Arctic). For investigating the possible impact of warm conveyor belts on the observed pollutant variability, we need to take into account full transport history from the source to the study area. This is currently being addressed in a separate study.

\section{Conclusions}

Although the long-range transport governs the variability of pollutants in the FT over the Nordic countries, it is the atmospheric weather states that finally determine the spatiotemporal distribution and the fate of the pollutants. The persistency of a particular weather state may further enhance or reduce concentrations of pollutants. Understanding the statistical link between weather states and pollution variability is not only crucial to understand the role of long-range transport itself, but also to be able to simulate such a link in chemistry transport models. The latter is important since chemistry transport models are often used to estimate changes in pollution load, attribution studies and developing mitigation strategies under different climate change scenarios. In this context, the present study attempts to provide insights into the sensitivity of free tropospheric carbon monoxide to different weather states and their degree of persistency based solely on observational data.

We investigated free tropospheric $\mathrm{CO}$ variability during eight weather states often prevailing over the Nordic countries. Selected states include four wind directions (NW, NE, SE, and SW), anticyclonic and cyclonic conditions, and positive and negative phases of the NAO. Furthermore, we investigated tendencies in $\mathrm{CO}$ under three different degrees of persistency (3-day, 5-day and 7-day) of each weather state. For nearly all the weather states, CO levels consistently continued to increase or decrease as the degree of their persistency increased. Among the weather states studied here, relatively speaking, the highest $\mathrm{CO}$ anomalies were observed when winds had southeasterly component, transporting pollutants from the central and eastern European regions to over the Nordic countries. The second largest contribution was from the northwesterly winds, most likely carrying pollutants as a result of long-range transport from polluted North American regions. The third largest anomalies are observed during enhanced positive phase of the North Atlantic Oscillation, confirming the importance of this natural variability in controlling pollutant distribution and transport over the study region. The cleanest conditions were observed under prevailing northeasterly winds and the enhanced negative phase of the NAO. The results from this sensitivity study provide an observational foundation for the process-oriented evaluation of chemistry transport models. 
It must be mentioned that although we provide relevant information on atmospheric circulation and meteorology while inferring the potential role of long-range pollution transport in the observed sensitivity of CO to weather states, the actual attribution and precise quantification of contribution from different transport pathways must be done using trajectory or chemistry transport models.

\section{The Supplement related to this article is available online at doi:10.5194/acp-14-11545-2014-supplement.}

Acknowledgements. We gratefully acknowledge the AIRS Science Team and NASA GES DISC for providing CO retrievals. The wind data from ERA-Interim reanalysis have been obtained from the ECMWF Data Server. We thank the three anonymous referees and the editor, Heini Wernli, for their constructive comments and suggestions to improve the paper. M. A. Thomas acknowledges funding support from the Monitoring Atmospheric Composition and Climate Phase II (MACC-II) project and A. Devasthale is grateful to the Swedish National Space Board (Rymdstyrelsen) for funding support.

Edited by: H. Wernli

\section{References}

AIRS Science Team/Joao Texeira: Aqua AIRS Level 3 Daily Standard Physical Retrieval (AIRS+AMSU),version 006, Greenbelt, MD, USA: NASA Goddard Earth Science Data and Information Services Center (GES DISC), doi:10.5067/AQUA/AIRS/DATA301, 2013.

AIRS-V6L3UG: AIRS Version 6 Level 3 data user guide, Edited by Baijun Tian, JLP/NASA, 1-37, available at: http://disc.sci.gsfc.nasa.gov/AIRS/documentation/v6_docs/ v6releasedocs-1/V6_L3_User_Guide.pdf, 2013.

Brandt, J., Silver, J. D., Frohn, L. M., Geels, C., Gross, A., Hansen, A. B., Hansen, K. M., Hedegaard, G. B., Skjøth, C. A., Villadsen, H., Zare, A., and Christensen, J. H.: An integrated model study for Europe and North America using the Danish Eulerian Hemispheric Model with focus on intercontinental transport, Atmos. Environ., 53, 156-176, doi:10.1016/j.atmosenv.2012.01.011, 2012.

Chahine, M. T., Pagano, T. S., Aumann, H. H., Atlas, R., Barnet, C., Blaisdell, J., Chen, L., Divakarla, M., Fetzer, E. J., Goldberg, M., Gautier, C., Granger, S., Hannon, S., Irion, F. W., Kakar, R., Kalnay, E., Lambrigtsen, B. H., Lee, S.-Y., Le Marshall, J., McMillan, W. W., McMillin, L., Olsen, E. T., Revercomb, H., Rosenkranz, P., Smith, W. L., Staelin, D., Strow, L. L., Susskind, J., Tobin, D., Wolf, W., and Zhou, L.: AIRS: Improving Weather Forecasting and Providing New Data on Greenhouse Gases, B. Am. Meteorol. Soc., 87, 911-926, 2006.

Chen, D.: A monthly circulation climatology for Sweden and its application to a winter temperature case study, Int. J. Climatology, 20, 1067-1076, 2000.
Chin, Mian, Diehl, T., Ginoux, P., and Malm, W.: Intercontinental transport of pollution and dust aerosols: implications for regional air quality, Atmos. Chem. Phys., 7, 5501-5517, doi:10.5194/acp7-5501-2007, 2007.

Christoudias, T., Pozzer, A., and Lelieveld, J.: Influence of the North Atlantic Oscillation on air pollution transport, Atmos. Chem. Phys., 12, 869-877, doi:10.5194/acp-12-869-2012, 2012.

Clerbaux, C., Boynard, A., Clarisse, L., George, M., Hadji-Lazaro, J., Herbin, H., Hurtmans, D., Pommier, M., Razavi, A., Turquety, S., Wespes, C., and Coheur, P.-F.: Monitoring of atmospheric composition using the thermal infrared IASI/MetOp sounder, Atmos. Chem. Phys., 9, 6041-6054, doi:10.5194/acp-9-6041-2009, 2009.

Creilson, J. K., Fishman, J., and Wozniak, A. E.: Intercontinental transport of tropospheric ozone: a study of its seasonal variability across the North Atlantic utilizing tropospheric ozone residuals and its relationship to the North Atlantic Oscillation, Atmos. Chem. Phys., 3, 2053-2066, doi:10.5194/acp-3-2053-2003, 2003.

Dee, D. P., Uppala, S. M., Simmons, A. J., Berrisford, P., Poli, P., Kobayashi, S., Andrae, U., Balmaseda, M. A., Balsamo, G., Bauer, P., Bechtold, P., Beljaars, A. C. M., van de Berg, L., Bidlot, J., Bormann, N., Delsol, C., Dragani, R., Fuentes, M., Geer, A. J., Haimberger, L., Healy, S. B., Hersbach, H., Hólm, E. V., Isaksen, L., Kållberg, P., Köhler, M., Matricardi, M., McNally, A. P., Monge-Sanz, B. M., Morcrette, J.-J., Park, B.-K., Peubey, C., de Rosnay, P., Tavolato, C., Thépaut, J.-N., and Vitart, F.: The ERA-Interim reanalysis: configuration and performance of the data assimilation system, Q. J. R. Meteorol. Soc., 137, 553-597, doi:10.1002/qj.828, 2011.

Dentener, F., Keating, T., and Akimoto, H. (Eds.): Hemispheric Transport of Air Pollution, United Nations, ISBN: 978-92-1117043-6, 2010.

Devasthale, A. and Thomas, M. A.: An investigation of statistical link between inversion strength and carbon monoxide over Scandinavia in winter using AIRS data, Atmos. Environ., 56, 109114, doi:10.1016/j.atmosenv.2012.03.042, 2012.

Devasthale, A., Willén, U., Karlsson, K.-G., and Jones, C. G.: Quantifying the clear-sky temperature inversion frequency and strength over the Arctic Ocean during summer and winter seasons from AIRS profiles, Atmos. Chem. Phys., 10, 5565-5572, doi:10.5194/acp-10-5565-2010, 2010.

Devasthale, A., Sedlar, J., and Tjernström, M.: Characteristics of water-vapour inversions observed over the Arctic by Atmospheric Infrared Sounder (AIRS) and radiosondes, Atmos. Chem. Phys., 11, 9813-9823, doi:10.5194/acp-11-9813-2011, 2011.

Devasthale, A., Tjernström, M., Caian, M., Thomas, M. A., Kahn, B. H., and Fetzer, E. J.: Influence of the Arctic Oscillation on the vertical distribution of clouds as observed by the A-Train constellation of satellites, Atmos. Chem. Phys., 12, 10535-10544, doi:10.5194/acp-12-10535-2012, 2012.

Devasthale, A., Sedlar, J., Koenigk, T., and Fetzer, E. J.: The thermodynamic state of the Arctic atmosphere observed by AIRS: comparisons during the record minimum sea ice extents of 2007 and 2012, Atmos. Chem. Phys., 13, 7441-7450, doi:10.5194/acp-13-7441-2013, 2013.

Divakarla, M. G., Barnet, C. D., Goldberg, M. D., McMillin, L. M., Maddy, E., Wolf, W., Zhou, L., and Liu, X.: Validation of Atmospheric Infrared Sounder temperature and water vapor retrievals 
with matched radiosonde measurements and forecasts, J. Geophys. Res., 111, D09S15, doi:10.1029/2005JD006116, 2006.

Duncan, B. N. and Bey, I.: A Modeling Study of the Export Pathways of Pollution from Europe: Seasonal and Interannual Variations (1987-1997), J. Geophys. Res., 109, D08301, doi:10.1029/2003JD004079, 2004.

Eckhardt, S., Stohl, A., Beirle, S., Spichtinger, N., James, P., Forster, C., Junker, C., Wagner, T., Platt, U., and Jennings, S. G.: The North Atlantic Oscillation controls air pollution transport to the Arctic, Atmos. Chem. Phys., 3, 1769-1778, doi:10.5194/acp-31769-2003, 2003

Fetzer, E. J.: Preface to special section: Validation of Atmospheric Infrared Sounder Observations, J. Geophys. Res., 111, D09S01, doi:10.1029/2005JD007020, 2006.

Fiore, A. M., Dentener, F. J., Wild, O., Cuvelier, C., Schultz, M. G., Hess, P., Textor, C., Schulz, M., Doherty, R. M., Horowitz, L. W., MacKenzie, I. A., Sanderson, M. G., Shindell, D. T., Stevenson, D. S., Szopa, S., Van Dingenen, R., Zeng, G., Atherton, C., Bergmann, D., Bey, I., Carmichael, G., Collins, W. J., Duncan, B. N., Faluvegi, G., Folberth, G., Gauss, M., Gong, S., Hauglustaine, D., Holloway, T., Isaksen, I. S. A., Jacob, D. J., Jonson, J. E., Kaminski, J. W., Keating, T. J., Lupu, A., Marmer, E., Montanaro, V., Park, R. J., Pitari, G., Pringle, K. J., Pyle, J. A., Schroeder, S., Vivanco, M. G., Wind, P., Wojcik, G., Wu, S., and Zuber, A.: Multimodel estimates of intercontinental sourcereceptor relationships for ozone pollution, J. Geophys. Res., 114, D04301, doi:10.1029/2008JD010816, 2009.

Huntrieser, H., Heland, J., Schlager, H., Forster, C., Stohl, A., Aufmhoff, H., Arnold, F., Scheel, H. E., Campana, M., Gilge, S., Eixmann, R., and Cooper, O.: Intercontinental air pollution transport from North America to Europe: Experimental evidence from airborne measurements and surface observations, J. Geophys. Res., 110, D01305, doi:10.1029/2004JD005045, 2005.

Hurrell, J. W., Kushnir, Y., Ottersen, G., and Visbeck, M.: An Overview of the North Atlantic Oscillation, in: The North Atlantic Oscillation: Climatic Significance and Environmental Impact, edited by: Hurrell, J. W., Kushnir, Y., Ottersen, G., and Visbeck, M., 1-35, Geophysical Monograph, 2003.

Li, Q., Jacob, D. J., Bey, I., Palmer, P. I., Duncan, B. N., Field, B. D., Martin, R. V., Fiore, A. M., Yantosca, R. M., Parrish, D. D., Simmonds, P. G., and Oltmans, S. J.: Transatlantic transport of pollution and its effects on surface ozone in Europe and North America, J. Geophys. Res., 107, ACH 107, doi:10.1029/2001Jd001422, 2002

Li, Q., Jiang, J. H., Wu, D. L., Read, W. G., Livesey, N. J., Waters, J. W., Zhang, Y., Wang, B., Filipiak, M. J., Davis, C. P., Turquety, S., Wu, S., Park, R. J., Yantosca, R. M., and Jacob, D. J.: Convective outflow of South Asian pollution: A global CTM simulation compared with EOS MLS observations, Geophys. Res. Lett., 32, L14826, doi:10.1029/2005GL022762, 2005.

Lin, M., Fiore, A., Horowitz, L. W., Cooper, O. R. R., Naik, V., Holloway, J. S., Johnson, B. J. J., Middlebrook, A. M., Oltmans, S. J. J., Pollack, I. B., Ryerson, T. B., Warner, J., Wiedinmyer, C., Wilson, J., and Wyman, B.: Transport of Asian ozone pollution into surface air over the western United States in spring, J. Geophys. Res., 117, D00V07, doi:10.1029/2011JD016961, 2012.

Linderson, M.-J.: Objective classification of atmospheric circulation over Southern Scandinavia, Int. J. Climatol., 21, 155-169, 2001.
Madonna, E., Wernli, H., Joos, H., and Martius, O.: Warm Conveyor Belts in the ERA-Interim Dataset (1979-2010). Part I: Climatology and Potential Vorticity Evolution, J. Climate, 27, 3-26. doi:10.1175/JCLI-D-12-00720.1, 2014.

Pfister, G., Petron, G., Emmons, L. K., Gille, J. C., Edwards, D. P., Lamarque, J.-F., Attie, J.-L., Granier, C., and Novelli, P. C.: Evaluation of $\mathrm{CO}$ simulations and the analysis of the CO budget for Europe, J. Geophys. Res., 109, D19304, doi:10.1029/2004JD004691, 2004.

Quinn, P. K., Shaw, G., Andrews, E., Dutton, E. G., RuohoAirola, T., and Gong, S. L.: Arctic Haze: Current trends and knowledge gaps, Tellus, 59B, 99-114, doi:10.1111/j.16000889.2006.00238.x, 2007.

Shindell, D. T., Chin, M., Dentener, F., Doherty, R. M., Faluvegi, G., Fiore, A. M., Hess, P., Koch, D. M., MacKenzie, I. A., Sanderson, M. G., Schultz, M. G., Schulz, M., Stevenson, D. S., Teich, H., Textor, C., Wild, O., Bergmann, D. J., Bey, I., Bian, H., Cuvelier, C., Duncan, B. N., Folberth, G., Horowitz, L. W., Jonson, J., Kaminski, J. W., Marmer, E., Park, R., Pringle, K. J., Schroeder, S., Szopa, S., Takemura, T., Zeng, G., Keating, T. J., and Zuber, A.: A multi-model assessment of pollution transport to the Arctic, Atmos. Chem. Phys., 8, 5353-5372, doi:10.5194/acp-85353-2008, 2008.

Stohl, A., Eckhardt, S., Forster, C., James, P., and Spichtinger, P.: On the pathways and timescales of intercontinental air pollution transport, J. Geophys. Res., 107, 4684, doi:10.1029/2001JD001396, 2002.

Susskind, J., Barnet, C., and Blaisdell, J.: Retrieval of Atmospheric and Surface Parameters from AIRS/AMSU/HSB Data in the Presence of Clouds IEEE T. Geosci. Remote, 41, 390-409, 2003.

Tang, L., Karlsson, P. E., Gu, Y., Chen, D., and Grennfelt, P.: Synoptic weather types and long-range transport patterns for ozone precursors during high-ozone events in Southern Sweden, Ambio, 38, 459-464, 2009.

Trickl, T., Cooper, O. R., Eisele, H., James, P., Mücke, R., and Stohl, A.: Intercontinental transport and its influence on the ozone concentrations over central Europe: Three case studies, J. Geophys. Res., 108, 8530, doi:10.1029/2002JD002735, 2003.

Warner, J. X., Comer, M. M., Barnet, C. D., McMillan, W. W., Wolf, W., Maddy, E., and Sachse, G.: A comparison of satellite tropospheric carbon monoxide measurements from AIRS and MOPITT during INTEX-A, J. Geophys. Res., 112, doi:10.1029/2006JD007925, 2007.

Warner, J. X., Wei, Z., Strow, L. L., Barnet, C. D., Sparling, L. C., Diskin, G., and Sachse, G.: Improved agreement of AIRS tropospheric carbon monoxide products with other EOS sensors using optimal estimation retrievals, Atmos. Chem. Phys., 10, 95219533, doi:10.5194/acp-10-9521-2010, 2010.

Warner, J. X., Carminati, F., Wei, Z., Lahoz, W., and Attié, J.L.: Tropospheric carbon monoxide variability from AIRS under clear and cloudy conditions, Atmos. Chem. Phys., 13, 1246912479, doi:10.5194/acp-13-12469-2013, 2013.

Yurganov, L. N., McMillan, W. W., Dzhola, A. V., Grechko, E. I., Jones, N. B., and van der Werf, G. R.: Global AIRS and MOPITT CO measurements: Validation, comparison, and links to biomass burning variations and carbon cycle, J. Geophys. Res., 113, D09301, doi:10.1029/2007JD009229, 2008. 